\title{
A OBSERVAÇÃO DEVISITANTES EM MUSEUS: SOBRE RATOS E SERES HUMANOS
}

\author{
Adriana Mortara Almeida* \\ Museu Histórico do Instituto Butantan
}

\section{RESUMO:}

O artigo apresenta uma revisão bibliográfica de estudos de público em museus que utilizam a observação dos visitantes como método de coleta de dados. Estudos inicialmente baseados na psicologia comportamental foram realizados nos Estados Unidos desde os anos 1920 e inspiraram muitas pesquisas posteriores. Abordagens etnográficas favoreceram a melhor compreensão dos comportamentos dos visitantes assim como o método da "Lembrança Estimulada". Dois estudos realizados pela autora em museus de arte de São Paulo são descritos e discutidos à luz da revisão bibliográfica inicial.

\section{PALAVRAS-CHAVE:}

Museu, Público, Observação, Etnografia,Avaliação.

\begin{abstract}
:
The article presents a literature review of museums' audience studies that use timing and tracking as a method of data collection. Studies initially based on behavioral psychology were performed in the United States since the 1920s and inspired many later studies. Ethnographic approaches favored a better understanding of the behavior of visitors as well as the method of "Stimulated Recall." Two studies by the author in art museums of São Paulo are described and discussed in light of the initial literature review.
\end{abstract}

\section{KEY-WORDS:}

Museum, Audience, Timing and tracking, Ethnography, Evaluation

\footnotetext{
* Historiadora, mestre e doutora em Ciências da Comunicação pela Escola de Comunicações e Artes da USP. Fez pós-doutorado em Museologia na UNICAMP, no Departamento de Geologia. Trabalhou como educadora do Museu de Arqueologia e Etnologia da USP por nove anos. Realizou inúmeras consultorias em diversos museus de São Paulo. Desde outubro de 2010 é diretora do Museu Histórico do Instituto Butantan. Atua no campo da educação, estudos de público e avaliação em museus e instituições culturais. É membro da atual diretoria do Comitê Brasileiro do ICOM (2012-20I5).
} 
O artigo pretende apresentar e analisar pesquisas de público em museus que utilizaram como metodologia a observação dos visitantes, identificando fatores em comum e diferenças entre as pesquisas e as vantagens dessa estratégia. Não tenho pretensão de esgotar o tema, apenas desejo trazê-lo para a discussão, também a partir de estudos que realizei em dois museus de São Paulo.

\section{A psicologia comportamental nos estudos de públicos em museus}

A publicação, em 2008, do texto de Bertha Lutz que relata suas visitas técnicas a museus norte-americanos, em 1932, permite conhecer o desenvolvimento das pesquisas de público em alguns museus dos Estados Unidos, a partir do olhar da pesquisadora. Alguns museus estavam desenvolvendo novas estratégias expográficas e educativas e precisavam saber se elas eram eficientes:

[...] museus americanos modernos empregam grande variedade de métodos educativos, como sejam as visitas com instrutores ou docentes, as palestras nas salas de exposição, as aulas, conferências, sessões recreativas, jogos, etc. Assim sendo, era inevitável que mais dia, menos dia, alguém se lembrasse da necessidade de investigar o valor relativo desses diferentes métodos, a fim de submetê-los ao processo de seleção, mormente em vista do dispêndio considerável acarretado por alguns deles, como sejam os dioramas ou habitat-groups (LUTZ, 2008, p. 33).

As pesquisas eram realizadas por psicólogos com objetivo de avaliar os melhores métodos de educação e divulgação por meio da análise de suas respostas a inúmeras questões colocadas e da identificação dos comportamentos de diferentes públicos. Por exemplo, no "Novo Museu de Ciências de Búfalo" (Buffalo Museum of Science), a pesquisa foi desenvolvida a partir de 1929 por Nita Goldberg, com crianças de grupos escolares visitantes. De forma experimental, Goldberg aplicava testes para que os alunos respondessem, verificando quais estratégias eram mais eficazes: uma palestra antes da visita de 15 ou de 30 minutos? Um jogo de busca nas exposições com cartões ou "visitas aos mostruários, com instrutoras científicas"? (LUTZ, 2008, p. 34). De acordo com as pesquisas, a palestra de 15 minutos levou a melhores resultados; os jogos de cartões funcionavam bem se as crianças conhecessem anteriormente o museu e sua distribuição espacial, para conseguir se orientar. Os testes também demonstraram que não há superioridade entre a estratégia dos jogos dos cartões e da visita à exposição com instruções e que a utilização dos dois métodos, conjuntamente, proporcionou melhores resultados.

As pesquisas desenvolvidas por Goldberg seguiam os preceitos da psicologia experimental, sempre criando grupos experimentais comparáveis, como descrito por Lutz (2008, p. 34):

[...] a sra. Goldberg pode trabalhar com grupos bastante grandes, constituindo unidades experimentais de 500 crianças. Ela mesma descreve o método como sendo de grupos paralelos, isto é, de idade, raça, ambiente social e inteligência semelhantes entre si.

Destaca-se a concepção de que a 'raça' seria uma variável a ser testada, assim como a idade e escolaridade, na comparação dos grupos experimen- 
tais. A leitura e análise dos jogos e testes aplicados, somada à identificação dos métodos de pesquisa empregados, revelam os pressupostos teóricos que envolvem a concepção de aprendizagem: a psicologia comportamental (behaviorista) e a concepção de aprendizagem baseada principalmente nos ganhos cognitivos, correspondentes a informações disponibilizadas por meio da observação dos objetos e da leitura dos textos das exposições.

Nita Goldberg também realizou observação de comportamento nas exposições e testou alguns recursos expositivos, especialmente os textos. Segundo Lutz (2008, p. 35), a pesquisadora verificou que "um rótulo pequeno em cada espécime interessa mais que os rótulos gerais grandes" e que "há grande superioridade no folheto descritivo da sala inteira sobre quaisquer rótulos, por melhores que sejam". As observações de Nita Goldberg seguiram metodologias desenvolvidas previamente por Edward Stevens Robinson, psicólogo da Yale University, responsável por realizar e coordenar pesquisas em museus com apoio da American Association of Museums e Carnegie Corporation of New York (ROBINSON, 1996, p.V).

Em publicação de 1928, Robinson relatou dois anos de pesquisas em museus de arte norte-americanos, nos quais foram realizadas observações nos museus e também de experimentos, como simulações em laboratório e interferências nas exposições (ROBINSON, 1928, p. I2)'. Com o intuito de diminuir o número de variáveis, como a presença de objetos de diversas tipologias, todos os estudos foram realizados em exposições de pinturas, em três diferentes museus ${ }^{2}$. Os visitantes espontâneos (casual visitors) eram observados por todo o percurso das salas previamente selecionadas.

Depois de várias observações, foram definidos os dados e comportamentos a serem registrados, considerando que poderiam ser obtidos de forma "mais completa e acurada, para cada visitante observado" (ROBINSON, 1928, p. 19):

I. Tempo total gasto na exposição de pinturas;

2. Salas nas quais entraram;

3. Número de pinturas, em cada sala, na frente das quais o visitante parou;

4. Tempo dedicado à observação de cada pintura (para aquelas nas quais o visitante parou para olhar).

Cerca de sessenta visitantes de cada museu foram observados, em dias de ingresso gratuito, de forma que os observadores não fossem identificados facilmente entre o público. Os resultados indicaram que nos museus menores, com menos salas e obras, os visitantes dedicaram mais tempo às

\footnotetext{
I Nos Estados Unidos, os estudos de Benjamin Gilman são considerados pioneiros nesse campo. Em um artigo publicado em 1916, Gilman descreve o esforço de um observador na exposição do Boston Museum of Fine Arts, especialmente no que se refere aos esforços muscular e mental necessários para ver os objetos, legendas e obras de arte nas vitrines e outros suportes da exposição. No artigo ele descreve a "fadiga museal" (museum fatigue) como sendo o cansaço do visitante em consequência do esforço dedicado a enxergar, ver e ler o que é apresentado nas exposições. Para ele, depois de gastar muita energia para ver algumas vitrines e obras, o visitante vai passar pelo resto da exposição apenas olhando tudo muito rapidamente. Ao final do artigo ele sugere algumas mudanças na expografia, especialmente em vitrines, para facilitar a apreciação da exposição (DAVEY, 2005; GILMAN, 1916; KÖPTCKE; PEREIRA, 20I0).
}

2 Robinson não cita os nomes dos três museus. Parte da pesquisa foi realizada em um quarto museu, porém com amostra menor que dos outros e cujos resultados são citados apenas parcialmente no artigo. 
obras e visitaram todas as salas, enquanto que no museu de maior porte, os visitantes circularam mais rapidamente, detendo-se menos em frente às obras e pulando diversas salas. Robinson afirma que não é possível generalizar tais resultados e que seria necessário empreender mais pesquisas para ter mais resultados e, possivelmente, fazer afirmações genéricas (ROBINSON, 1928).

Robinson discute a utilização do termo 'fadiga' que costuma ser usado para o fenômeno observado, e para a explicação do mesmo ${ }^{3}$. Nesse sentido, ele afirma que existem diferentes formas de fadiga, como, por exemplo, a física, por andar muito, olhar muito; ou a mental, por ter que processar muita informação. Fatores como o número total de obras nas salas, a maneira como estão expostas (em linhas sucessivas, isoladamente, em diversas alturas) poderiam interferir na 'fadiga museal'.

Por meio de análise dos dados obtidos ${ }^{4}$, Robinson mostra que o tempo dedicado às obras selecionadas pelos visitantes para observação decresce ao longo da visita, como se poderia esperar a partir da ideia de que com o tempo o visitante vai perdendo interesse por causa da "fadiga museal". Entretanto, esse decréscimo não é regular e contínuo, sugerindo que outras variáveis, além do tempo dedicado à visitação, sejam relevantes. Por exemplo, na primeira parte da visita, o tempo dedicado às obras cresce, o que Robinson atribui a um "aquecimento" para a visita (ROBINSON, 1928, p. 40-4I).

Robinson (1928, p. 44) buscou outros fatores, denominados por ele "extrínsecos", que pudessem explicar as paradas e o tempo de observação das obras pelos visitantes. A partir dos resultados, ele enumerou os fatores ou conjunto de fatores que aumentam a probabilidade de uma obra ser observada, em ordem de eficácia:

I. Dimensão grande e posição central, conjuntamente;

2. Dimensão e posição no final apenas (ambos em segundo lugar);

3. Dimensão e posição no final, conjuntamente;

4. Dimensão combinada com isolamento;

5. Isolamento apenas;

6. Posição central apenas.

O autor realizou vários testes laboratoriais com estudantes para verificar a influência desses fatores para a "fadiga museal". Realizou também experiências nos museus com folhetos que destacavam algumas obras, que eram entregues aos visitantes e que, pelos resultados obtidos, levaram os visitantes a aumentar o número médio de salas, de obras observadas e de tempo de observação (ROBINSON, 1928, p. 53-65).

Arthur Melton, também da Yale University ${ }^{5}$, desenvolveu inúmeras pesquisas em museus, inicialmente sob coordenação de Edward Robinson (MELTON; FELDMAN; MASON, 1996) e posteriormente liderando outros psicó-

3 Davey (2005) faz uma interessante análise das pesquisas que tratam da "fadiga museal", reunindo várias fontes.

4 Para comparar os dados obtidos nos museus, Robinson conduziu um experimento em laboratório para o qual convidou estudantes a observarem uma sucessão de 100 obras (reproduções), indicando em que momento já teriam observado satisfatoriamente cada obra, para que outra obra fosse apresentada. O tempo de observação de cada obra foi maior do que dos visitantes nos museus, chegando a 28 segundos, enquanto que nos museus não ultrapassou 19 segundos e a curva de tempo de observação teve um decréscimo mais acentuado do que nos museus. (ROBINSON, 1928, p. 35-38). 
logos. Sobre sua pesquisa realizada no Philadelphia Art Museum, Lutz (2008, p. 35) cita, especialmente, a 'descoberta' de que "a maioria de visitantes americanos só examina as obras de arte que ocupam a parede direita do Museu [...]".

Melton também realizou pesquisas em outros tipos de museus. Em seu artigo de 1936, descreve a pesquisa realizada no New York Museum of Science and Industry com objetivo de identificar as formas mais eficientes de módulos de exposição (exhibits) para esse tipo de museu. Fez experimentos nas exposições de máquinas, com movimentação periódica de grandes máquinas, de forma automática ou por acionamento dos visitantes, para identificar a variação no grau de atração e distração desses módulos expositivos (máquinas) e dos outros módulos em exposição na mesma sala. Assim como Robinson, Melton registrou o percurso, marcando as paradas, a leitura de legendas e manipulação das máquinas (MELTON, 1936). A necessidade de saber mais sobre cada um dos visitantes ${ }^{6}$ não existia, uma vez que os pressupostos eram de que os visitantes selecionados aleatoriamente representavam a média dos visitantes em geral.As experiências prévias de cada visitante não eram consideradas uma variável significativa para as pesquisas, de acordo com a linha da psicologia comportamental adotada.

Outros estudos vão seguir a mesma linha como os desenvolvidos por Bigman (1956), Goins e Griffehagen (1957). Estes últimos utilizam conceitos construídos a partir das pesquisas anteriores: poder de atração (attracting power) e poder de retenção (holding power), que correspondem à capacidade de um elemento da exposição atrair o visitante e fazê-lo parar para observá-la e a capacidade de um módulo da exposição manter por mais tempo o olhar do visitante, respectivamente. Os registros dos percursos, dos pontos de parada, dos tempos dedicados a cada parte do percurso (timing and tracking), foram descritos por Yalowitz e Bronnenkant (2009) como sendo inicialmente apenas uma ferramenta de registro físico por onde o visitante circulava na exposição.

In more recent times tracking visitors refers more specifically to recording, in a detailed manner, not only where visitors go but also what visitors do while inside an exhibition. It can provide quantitative data in relation to stay times as well as other behavioral data. [...] (YALOWITZ; BRONNENKANT, 2009, p. 48).

A observação dos visitantes, como se fossem cobaias de experiências laboratoriais, para encontrar comportamentos padrão, como o desejo de sair sempre que há uma porta de saída e a tendência de virar à direita, é duramente criticada por Lawrence (1993, p. I I7):

From an experimenting involving the making of a second exit in a gallery Melton concluded that:'The exit [...] acts as an extremely interesting object and competes with the art objects for attention'. Melton made many similar experiments on the presumed rat-like visitor by altering the museum maze. Focus on temporo-spatial behavioral change alone led him to conflate attraction to an exit and to an object.

Lawrence (1993, p. II8) chama atenção para o fato de que por muito tempo a psicologia dominou os estudos de públicos em museus, e que também os psicólogos cognitivistas valorizaram a observação e comportamentos:

6 Melton (1936) optou por observar os visitantes desacompanhados, com intuito de diminuir as variáveis relacionadas à interação com outras pessoas. 
Cognitive psychologists continued to study behavior, but primarily in order to theorize the unobservable constructs - ideas, motives and other conscious elements - that might explain it. This change, great as it was, did not, however, involve a rejection of the empirical methods of objective observation and casual generalization.

A partir de novos pressupostos teóricos, a observação dos visitantes continuou a ser realizada como estratégia para compreensão da experiência dos visitantes e para identificação das melhores maneiras de realizar exposições e ações educativas.

Nos Estados Unidos, outra linha de pesquisa que envolvia a observação de visitantes de museus foi chamada de "estratégia naturalista" (Naturalistic Strategy) e divulgada a partir do final dos anos 1970, especialmente por um grupo de pesquisadores ligados a Smithsonian Institution, em Washington DC. A metodologia era sugerida principalmente para a avaliação de exposições. De acordo com Wolf (1980, p. 39-40),

[...] evaluation becomes naturalistic if it: $(I)$ focuses on current and spontaneous activities, behaviors and expressions rather than a narrow set of pre-specified objectives; (2) responds to staff members' needs for different kinds of information; and (3) accounts for the different values and perspectives that exists whenever the question of impact is introduced. [...] Naturalistic evaluation procedures attempt to capture what actually occurs in museum settings. Such procedures focus on persons as they are engaged in performing their museum responsibilities or on visitors as they are engaged in their museum experience.

Os procedimentos para observação não são previamente definidos, devendo ser construídos ao longo da pesquisa, a partir do trabalho 'em campo', ou seja, da observação dos visitantes, de como eles interagem com as exposições e entre si. Segundo Wolf (1980, p. 42), um típico estudo inclui quatro fases operacionais:

I. Negociação: definição de recursos disponíveis e motivações para a pesquisa. Nesta fase podem ser realizadas entrevistas com equipe do museu para definir potenciais questões de pesquisa e, em seguida, desenvolve-se a observação do comportamento dos visitantes para auxiliar no próximo passo.

2. Identificação da questão a partir da discussão dos dados obtidos até esse momento (da equipe e dos visitantes).

3. Investigação em profundidade: a partir da questão levantada, novas observações e entrevistas são realizadas e sistematicamente discutidas com a equipe para ir ajustando as estratégias para que se obtenham informações relevantes.

4. Análise dos dados e apresentação dos resultados para a equipe do museu para aumentar a possibilidade da avaliação ser utilizada pela equipe do museu.

De natureza qualitativa, a estratégia naturalista propunha estudar os seres humanos em suas relações "naturais" e não previa a realização de experimentos para testar determinadas hipóteses. Essa abordagem é amplamente utilizada pela antropologia, em estudos qualitativos, os quais pretendem dar 
o protagonismo de cada fenômeno estudado aos indivíduos em suas diversas formas de ação e manifestação. Nesse sentido, as ações sociais obedecem a intenções, atitudes, crenças, valores, significados, sentimentos, que não podem ser reduzidos a uma lei quantitativa.

A valorização de cada um dos sujeitos da pesquisa, da maneira que ele se apropria das exposições está presente na etnografia, abordagem qualitativa da antropologia, que passa a ser utilizada por pesquisadores para compreender a experiência dos visitantes dos museus.

\section{Estudos etnográficos}

A partir da observação dos percursos de cada visitante de uma exposição temporária no Centre George Pompidou de Paris, de junho a outubro de 1982, Verón e Levasseur (1989) identificaram tipos de percursos e estes foram os critérios para definir tipos de públicos. Os pressupostos teóricos da pesquisa se distanciavam da psicologia, uma vez que se baseavam na ideia de que a exposição é um discurso, diferente para cada visitante, que constrói sua própria exposição a partir das suas escolhas de percurso. Trata-se de um estudo de recepção, de apropriação do discurso proposto pela exposição. Para os autores a visita à exposição é uma negociação entre o visitante e aquele que concebeu a exposição (curador, instituição etc). Os comportamentos dos visitantes são vistos como modalidades de apropriação. "Pois se ex-por é sempre pro-por, visitar uma exposição é com-por, nos dois sentidos do termo: aquele de produzir uma combinação, e o de se acomodar" (VERÓN; LEVASSEUR, 1989, p. 21). E "se acomodar" aparece aqui no sentido de negociar, negociar a relação com a exposição e, portanto, com o expositor.

Uma exposição realiza-se com a colocação no espaço de painéis, textos, imagens, objetos, cenários, entre outros, que definem uma série de percursos possíveis que serão atualizados conforme o procedimento de interação/ negociação de cada visitante. Ao observar o comportamento do visitante, não de forma behaviorista numa relação de causa-efeito, mas considerando o papel ativo do visitante, os autores pretendem perceber como se dá a apropriação da exposição.

$\mathrm{Na}$ introdução do livro de Verón e Levasseur (1989), Jean-François Barbier-Bonet deixa claro que já existem inúmeras pesquisas quantitativas sobre o perfil dos visitantes do Centro Georges Pompidou (Beaubourg) e que a pesquisa ali apresentada, mesmo que em situação particular, tem dupla ambição / duplo registro: "[...] o registro cultural (encontrar resultados transponíveis ao público de outras exposições), e o registro sociológico (elaborar uma problemática e testar metodologias reutilizáveis em outros locais)" (VERON; LEVASSEUR, 1989, p. 8). Fazendo a observação direta do percurso de visitação, os pesquisadores pretendiam entender o processo de interação/leitura da exposição.

Inicialmente, os pesquisadores fizeram uma análise semiológica da exposição. Em seguida, observaram e registraram os percursos dos visitantes. Depois de observar e registrar inúmeros visitantes, os pesquisadores identificaram quatro modos de visita / percurso que se repetiam com frequência, agrupando os visitantes em: as "formigas" (ou visita proximal), as "borboletas" (ou visita pendular), os "peixes" (ou visita deslizante) e os "gafanhotos" (ou visita 'punctum') (VERÓN; LEVASSEUR, 1989, p. 62). 
$\mathrm{Na}$ última etapa realizaram entrevistas com alguns visitantes, envolvendo a visão sobre a exposição, sobre o Centre G. Pompidou, seus dados sociodemográficos e suas motivações para a visita, além de retomar conjuntamente o percurso que teria feito ao visitar a exposição. Nesta etapa, a questão norteadora era saber se os visitantes que tiveram a mesma forma de apropriação da exposição (o mesmo tipo de percurso) também tinham outras características em comum. A análise das entrevistas evidenciou que a "tipologia dada pela observação dos comportamentos remete bem a uma tipologia mais fundamental das atitudes frente à exposição, em particular e, mais genericamente, ao consumo cultural" (VERÓN; LEVASSEUR, 1989, p. 70).

No Brasil, as primeiras pesquisas etnográficas em museus mais consistentes foram desenvolvidas por pós-graduandas da Pontifícia Universidade Católica do Rio de Janeiro, no programa de Educação e apresentadas em suas dissertações de mestrado. Em 1992, Freire apresentou dissertação sobre a ação educativa do Museu do Folclore Edson Carneiro (RJ), especialmente no que tange a formação de professores e a atuação dos mesmos durante as visita de seus alunos. Por meio da observação e entrevista dos professores, Freire percebeu que o que era afirmado no discurso dos professores, como o objetivo da visita ser o enriquecimento do que foi trabalhado em aula e a contribuição para elevar a autoestima dos alunos, não se dava na prática, que era disciplinadora e que acabava aumentando o distanciamento dos alunos com a exposição (FREIRE, 1992, p. I 19).

No mesmo ano, Cazelli apresentou dissertação sobre o trabalho educativo do Museu de Astronomia e Ciências Afins (MAST-RJ), na qual abordava a participação dos professores tanto na preparação como durante a visita ao MAST, com objetivo de refletir sobre o papel social dos museus interativos enquanto espaços de educação pública e aperfeiçoamento da alfabetização científica (CAZELLI, I992, p. 5). Por meio da observação de reuniões de professores, visitas escolares e entrevistas com professores, Cazelli (1992) investigou a percepção dos professores sobre a ciência, os museus de ciência, educação em ciência e sobre o MAST.

Freire (1992) e Cazelli (1992) utilizaram a metodologia etnográfica da descrição densa, inspirada em Clifford Geertz, para descrever e analisar a participação dos professores e as relações estabelecidas entre museus e escolas ${ }^{7}$. A descrição densa busca compreender os significados atrás das ações ou comportamentos dos indivíduos.

Aplicando a mesma metodologia, Valente estudou o público do Museu Nacional (RJ), entre setembro de 1993 e abril de 1994, com objetivo de avaliar alguns aspectos das exposições do Museu. Seu foco foi o público espontâneo, adulto, do qual registrou percurso e falas.

A observação centrou-se em captar a percepção e expressão do visitante, registrando os comportamentos relacionados a três aspectos: apresentação, exposição, objeto exposto e atitude, visitante. Ao longo da dissertação, Valente (1995) descreve algumas "cenas" observadas, trazendo os gestos, as falas e ideias dos visitantes. Percebe-se nas cenas que, pela qualidade da apresentação, as etiquetas não são compreendidas e a concepção da apresentação exclui os indivíduos que têm apreensão difícil. Em vez de o museu desmistifi-

7 Freire (1992) também utilizou como referencial teórico Arnold Van Gennep, ao interpretar a visita educativa como um ritual. 
car a ciência, ele parece cristalizar imagens previamente construídas (VALENTE, 199, p. 157). Para Valente (1995, p. 155) "[...] a apresentação do acervo e dos temas de história natural ou de antropologia física não consegue transmitir informações e promover interação com o público."

Mais recentemente, Dutra investigou a visita escolar em museus a partir de pesquisa documental e observação etnográfica. Seu objetivo, similar aos de Freire (1992) e Cazelli (1992), era de compreender as relações estabelecidas entre museus e escolas:

[...] o fenômeno a ser investigado é a visita escolar ao museu, em busca da compreensão do que ocorre quando escolas e museu se encontram: de que forma museu e escola compõem a cena pedagógica e quais dimensões formativas são mobilizadas no momento em que esses contextos educativos estão em contato? (DUTRA, 2012, p. 32).

Durante um ano, Dutra (20I2) observou visitas escolares ao Museu Histórico Abílio Barreto, em Belo Horizonte, e entrevistou professores. Além disso, analisou respostas dos professores às questões respondidas em formulários preenchidos por eles, no dia da visita ao Museu. As anotações realizadas durante a observação das visitas, inspiradas na descrição densa, serviram de base para a melhor compreensão da experiência dos grupos de estudantes no museu.

\section{Outras abordagens}

Muitos outros estudos que partem da observação de visitantes de museus foram realizados, com diversas metodologias, especialmente com o intuito de verificar a aprendizagem.

Borun, Chambers e Cleghorn (1996) observaram e descreveram o comportamento de visitantes (famílias) para verificar aprendizagem. Determinaram-se treze categorias de comportamento ${ }^{8}$ para observação e considerou-se que esses comportamentos correspondiam a três diferentes níveis de aprendizagem: Identificação, Descrição, e Interpretação e Aplicação. Alguns comportamentos não implicaram na variação de níveis de aprendizagem (por exemplo, aproximar ou apontar), enquanto outros foram significativos (por exemplo, perguntar, ler em voz alta, entre outros). Para realizar todos os registros necessários foram feitas gravações em áudio e vídeo e também foram realizadas entrevistas para coleta de dados demográficos e opiniões sobre o módulo observado (BORUN; CHAMBERS; CLEGHORN, I996, p. I24-I25).

Falcão e Gilbert (2005, p. 94) desenvolvem pesquisas de aprendizagem em museus utilizando o método da Lembrança Estimulada (Stimulated Recall Method), definido como:

[...] um grupo de métodos de pesquisa em que o sujeito é exposto a registros (audioteipes, fotografias, videoteipes, escritos, desenhos) relacionados a uma atividade específica da qual participou (aulas, conferências, sessão de análise etc.). Entende-se que os registros funcionam como pistas que capacitam os participantes a se lembrarem de um episódio em que tiveram uma experiência específica, tornando-os capazes de expressar verbalmente os pensamentos que desenvolveram durante a atividade, assim como quaisquer crenças relevantes, concepções e comentários em geral.

8 Aproximar, Chamar, Apontar, Perguntar, Responder, Comentar/explicar, Ler em voz alta, Ler silenciosamente, Subir, Manipular, Expressar apreciação, Expressar desagrado, Afastar-se. 
As visitas ao museu são observadas, filmadas e/ou fotografadas e, em seguida, as imagens são mostradas aos visitantes observados. Estes veem as imagens e são estimulados a falar sobre o que pensaram, o que faziam, entre outras relações com as imagens. Para os autores,

Entendemos que a principal contribuição da LE, nos museus de ciências, é facilitar o participante a expressar o significado de suas experiências, assim como as razões para suas ações e escolhas ao longo da visita. A sequência de fotos, no caso dos visitantes, e o vídeo, no caso dos mediadores, trazem para a avaliação muitas situações de aprendizagem que ocorrem na visita e que, certamente, escapariam a outras metodologias. Neste sentido, o uso da LE pode trazer subsídios relevantes para a pesquisa sobre aprendizagem em museus de ciências (FALCÃO; GILBERT, 2005, p. I I 3).

O método da Lembrança Estimulada foi utilizado em pesquisas desenvolvidas em museus por alunos de Martha Marandino, da Faculdade de Educação da Universidade de São Paulo (FEUSP), visando a compreender melhor o processo de aprendizagem nesses espaços. ${ }^{9}$

John Falk, Lynn Dierking e outros pesquisadores do Institute of Learning Innovation (EUA) desenvolvem, há mais de três décadas, pesquisas em museus, visando a compreender a experiência museal e avaliar a aprendizagem, utilizando constantemente a observação dos visitantes como uma das estratégias de pesquisa. Combinada à observação, outras estratégias, como entrevistas logo após a visita e tempos depois (um mês ou mais), além de aplicação de questionários são utilizadas para compreender de forma aprofundada o que se passa com cada visitante e o que ele aprende. (FALK, 1982; FALK; DIERKING, 1992; FALK; DIERKING, 2002; ALMEIDA, 2004, 2005).

Os estudos indicam a necessidade de combinação de diversas metodologias: a observação isolada pode levar a interpretações distantes da realidade sendo, portanto, fundamental combiná-la com entrevistas, questionários e, se possível, levantamentos quantitativos que contextualizem o que está sendo investigado.

Muitas outras pesquisas com diversas abordagens, que envolvem a observação do público em museus, foram desenvolvidas. Não se pretende aqui esgotar o tema. É importante indicar que muitos dos autores aqui apresentados serviram de base para a construção das pesquisas de público que realizei no Museu Lasar Segall (ALMEIDA, 200I, 2002) e na Pinacoteca do Estado de São Paulo (ALMEIDA, 2008).

\section{Reflexões sobre dois estudos desenvolvidos}

Os dois estudos de público mais longos que desenvolvi utilizando a observação dos visitantes dos museus foram realizados na exposição de longa duração do Museu Lasar Segall, nos anos 2000 e 200 I e na exposição de longa duração da Pinacoteca do Estado, em 2008. Em ambos os casos, a realização da avaliação buscava recolher dados que pudessem subsidiar a reformulação das respectivas exposições, por iniciativa das instituições responsáveis ${ }^{10}$. No caso do Museu Lasar Segall (MLS) também foi feita a avaliação da ação educativa na exposição (ALMEIDA, 2002).

9 Por exemplo, as dissertações de mestrado de Sápiras (2007) e de Garcia (2006).

10 As reformulações da exposição de longa duração na Pinacoteca do Estado, realizadas entre 2010 e 201 I, tiveram como base diversas fontes, entre elas a pesquisa de público aqui citada. 


\section{Museu Lasar Segall}

A pesquisa teve diferentes fases: incialmente buscou-se sistematizar informações que já tinham sido coletadas, referentes aos visitantes do museu, e que nunca tinham sido analisadas: os poucos dados disponíveis em breves formulários respondidos pelos visitantes espontâneos à entrada do MLS de 1997, 1998 e 1999 serviram de base para delimitar o universo de visitantes". Em seguida foi realizada a descrição da exposição, colocando em uma planta baixa a maior parte do mobiliário e das obras em exposição, de forma a facilitar o registro dos percursos dos visitantes.

Entre os meses de maio e agosto de 2000, visitantes espontâneos de 15 anos ou mais foram observados e entrevistados na exposição de longa duração do MLS.

O registro foi realizado por meio da observação do percurso na exposição, destacando-se os seguintes itens:

- Tempo de visitação;

- Percurso, incluindo parada (mais de 30 segundos no mesmo ponto), leitura de textos de parede (considerada quando visitante permanecia mais de 30 segundos diante do texto, olhando para o mesmo), observação de vitrines e observação de obras (pinturas nas paredes e esculturas em pedestais);

- Manipulação de gavetas (abrir e fechar gavetas presentes nas vitrines), manipulação dos trainéis (com obras em papel) e manipulação do "Exercício de Leitura" (Caderno criado pelo MLS para relacionar um pequeno número de obras em um "nicho" da exposição);

- Interação entre os visitantes.

Naquele momento, consideramos que o comportamento do público no espaço expositivo poderia trazer os pontos de "atração", "retenção" e até aqueles que "repelem" os visitantes, mostrando pontos positivos e negativos da expografia.Os dados da observação de 115 visitantes indicaram alguns comportamentos (ALMEIDA, 2000, p. I I3-140):

- Número de paradas: 44,4\% pararam de I a 8 vezes (mais de 30 segundos), principalmente para ler textos ou para olhar para vitrines, gavetas e o Exercício de Leitura.

- Observação de vitrines:56,5\% olharam de 3 a 6 vitrines (de um total de 8).

- Dos 94 visitantes observados em junho, julho e agosto, somente 2 não olharam para as vitrines.A média foi de 5,5 vitrines por visitante.

- Manipulação de gavetas: $42,6 \%$ não abriram gavetas. $29,5 \%$ abriram de I a 8 gavetas (de um total de 68 visitantes que abriram).

- Leitura de textos: $76 \%$ dos 94 visitantes leram pelo menos I texto. A média foi de 3 textos por visitante (de um total de 13 textos).

- Manipulação dos trainéis: os trainéis atraíram os visitantes, mas não os retiveram por muito tempo. Dos 94 visitantes, $65,9 \%$ não pararam para ver os trainéis. Dos 32 que pararam, 6 ficaram mais de 5 minutos e puxaram mais de 2 painéis.

- Manipulação do Exercício de Leitura: Esse módulo foi o que mais

II Os dados eram: Nome, local de residência, faixa etária, sexo e ocupação profissional. Não será apresentada aqui a avaliação da ação educativa. 
reteve os visitantes.A maior parte dos visitantes parou para olhá-lo e para manipulá-lo por um bom tempo. Algumas pessoas ficaram mais de 20 minutos. Dos 94 visitantes, 10 pararam por mais de 10 minutos para manipular e ler o texto e observar as obras de arte. O Exercício também estimulou a conversação entre os visitantes.

Ao final do percurso, os visitantes eram entrevistados para levantamento de seu perfil sociodemográfico e de hábitos culturais, motivação para a visita, comportamentos durante a visita, compreensão e preferências em relação à exposição, sentimentos provocados pelas obras e sugestões.

Os visitantes eram observados em seu percurso pela exposição "Lasar Segall: Construção e Poética de uma Obra" sem serem previamente avisados e, ao final, eram solicitados a responder algumas perguntas ${ }^{12}$.

Entre as perguntas, algumas tratavam dos comportamentos observados: Você abriu as gavetas? Você leu os textos das paredes? Em ambos os casos, se o visitante respondesse que "não", perguntávamos o porquê de não abrir ou não ler. No caso da resposta ser positiva, perguntávamos sua opinião sobre os conteúdos das gavetas ou dos textos.

Esse procedimento garantiu, como citado anteriormente, a compreensão de "o porquê as pessoas se comportam assim" (YALOWITZ;BRONNENKANT, 2009, p. 49). Por exemplo, alguns visitantes que não abriram as gavetas das vitrines afirmaram que não o fizeram "porque não sabiam que poderiam abrir" e outros "porque já tinham aberto em ocasiões anteriores". Ou seja, o comportamento de não abrir as gavetas pode ser explicado pela falta de interesse ou tempo, mas também pelos motivos indicados na fala dos respondentes.

A parada, ou não, diante de uma obra variou, sendo que a maior parte dos visitantes viu todas as obras das paredes de forma rápida. Paradas (mais de 30 segundos) para observar obras foram menos frequentes do que para olhar vitrinas ou ler textos. De 94 visitantes observados entre junho e agosto de $2000^{13}$, a média foi de I,7 paradas para observar obras (de um total de 115 obras). A pintura Navio de Emigrantes foi a mais observada: 48,9\% dos 94 visitantes pararam para apreciá-la. Em segundo lugar ficou a tela Interior de Pobres II com 27,6\%. Esta obra não estava na exposição até junho, quando percebemos que as paradas nessa parte da exposição se tornaram frequentes. Durante os meses de abril e maio, não foram observadas paradas para olhar as obras que a substituíam. Apesar da atenção dos visitantes, ela só foi citada por um visitante (entre todos os 206 entrevistados) como a parte favorita da exposição.

Então, o que teria feito as pessoas fixarem seu olhar nesta obra? A princípio, poderíamos afirmar que não é sua localização, uma vez que as obras que estavam no mesmo lugar anteriormente não foram alvo da mesma atenção. Sua dimensão poderia ser uma das explicações (I40,0 x 173,0 cm), uma vez que é maior do que as três obras que ocupavam o mesmo espaço antes no início do ano 2000.

\footnotetext{
12 As perguntas foram testadas, num primeiro momento, e depois consolidadas em um questionário que servia de roteiro para a entrevista. Depois de cerca de um mês de aplicação, foi inserida uma questão nova: "Quais sentimentos ou sensações a exposição suscitou em você?”, sugerida pela equipe do MLS.

13 Durante a pesquisa, foram entrevistados 206 visitantes. Entre esses, I I 5 foram também observados, sendo que 21 entre 12 de abril e 10 de maio de 2000 e 94 entre 17 de junho e 08 de agosto de 2000 . Em maio houve uma greve dos funcionários do MLS que fechou a exposição. Na reabertura, em junho, foram acrescentadas obras do acervo que estavam emprestadas para uma exposição no exterior.
} 
A obra apresenta outras características que atraem o olhar do visitante: figuras humanas com expressões de tristeza, um ambiente aparentemente doméstico, simples e pouco colorido ${ }^{14}$.

A observação do comportamento das pessoas não vem acompanhada de explicações. Entretanto, quando perguntamos "Quais sentimentos ou sensações a exposição suscitou em você?" muitas respostas (16\%) se referiam ao sentimento de tristeza e angústia causado pelas obras observadas:"Algumas obras causam tristeza.”; "Melancolia de recordação."; "Muito triste, cores pesadas." São alguns exemplos das respostas dos visitantes (ALMEIDA, 2000, p. 107). Essas respostas evidenciam a possibilidade de uma obra de temática triste provocar atração nos visitantes, fazendo-os parar para observá-la.

Considero que muitos dos pressupostos iniciais dessa pesquisa no MLS tinham forte influência da psicologia comportamental, apesar de que já conhecia outras abordagens. Entretanto, no decorrer do processo de pesquisa, houve um afastamento desse referencial e uma aproximação com referenciais da antropologia e da comunicação, que embasaram a descrição e análise dos dados levantados. Esse afastamento se deu pela impossibilidade de resolver os problemas e questões que as observações indicavam.

\section{Pinacoteca do Estado de São Paulo}

A exposição de longa duração da Pinacoteca do Estado é muito maior do que a do Lasar Segall, tanto em área, número de salas, como na quantidade de obras expostas. Em 2008, a exposição de longa duração da Pinacoteca ocupava todo o segundo piso do prédio da Praça da Luz, contando com I5 salas e mais seis espaços expositivos (átrios e corredores), com cerca de 800 obras do acervo em exibição. Sua organização era cronológica, a partir do século $X I X^{15}$, e incluía algumas salas temáticas e de artistas, além dos átrios, com destaque para o das esculturas francesas, e os corredores ${ }^{16}$.

Para realizar o percurso cronológico proposto, o visitante precisava acessar o segundo andar pelo elevador, sair para a direita e adentrar a exposição através de uma porta de vidro dotada de grande painel que a apresentava "Acervo da Pinacoteca, século XIX ao XXI". A partir dessa sala o visitante deveria virar para a esquerda e seguir o percurso.

Os 210 visitantes que tiveram seus percursos registrados não realizaram a visita na ordem proposta e apenas cinco destes visitantes entraram em todas as salas ${ }^{17}$. O objetivo da avaliação foi conhecer a experiência vivenciada pelos visitantes na exposição de longa duração ou em parte dela, levantando os seguintes pontos, por meio da observação e entrevista:

I. O percurso realizado - apreciação e sugestões

2. Os pontos de maior atração

3. Os pontos de maior retenção

I4 A reprodução dessa obra pode ser visualizada no website do Museu Lasar Segall. Disponível em: $<$ www.museusegall.org.br>.

I5 Havia algumas obras mais antigas, especialmente sacras, na primeira sala da exposição.

16 Todos os dados aqui apresentados foram extraídos de Almeida (2008).

17 Para efeito desta avaliação, algumas salas foram subdivididas em partes, de maneira que quando afirmo que entraram em TODAS as salas, quero dizer que percorreram todas as partes de todas as salas da exposição de longa duração. 
4. Os pontos não percorridos e / ou olhados

5. A quantidade de obras apresentadas / o tamanho da exposição

6. As obras preferidas / As obras não apreciadas

7. A sinalização e orientação - dificuldades observadas e relatadas

8. Os textos - apreciação e sugestões

9. As legendas - apreciação e sugestões

10. 10.A expografia - apreciação e sugestões

II. Os conteúdos apresentados - noções e sugestões.

Em uma das fases da pesquisa foram feitas questões sobre leitura e apreciação das legendas e textos. Foram também feitas perguntas abertas sobre a qualidade da orientação visual e sobre a forma de apresentação das obras. O visitante indicava também o de que mais gostou na exposição e o de que mais sentiu falta. Outra questão, criada com o objetivo de identificar se o respondente percebia a exposição como um conjunto, solicitava que ele a resumisse em uma única frase. As perguntas referentes ao perfil e aos hábitos de visitação não foram modificadas ao longo da pesquisa.

Em outra fase do trabalho foram feitas perguntas sobre preferências de forma de apresentação de textos, legendas e orientação visual (localização, tamanho, distribuição na exposição, impressos ou em áudio). Também foi perguntado aos visitantes sobre a retirada ou não de obras da "Sala de Retratos", sobre as preferências em relação à ação dos educadores e sobre a organização da exposição.

Após observar e registrar 210 visitantes, obtivemos 210 percursos diferentes, o que demonstra que cada um deles construiu a sua experiência particular de visita.

Apenas $28 \%$ dos visitantes observados chegaram ao $2^{\circ}$ andar pelo elevador principal. E a maior parte destes visitantes saiu do elevador e dirigiu-se para o lado esquerdo, em direção ao átrio e, não, para o lado direito, em direção à sala das "Paisagens Marinhas" que, teoricamente, seria o início da exposição.

Quatro dos cinco visitantes que percorreram todas as salas estavam acompanhados, passeando e / ou conhecendo o museu, ou mostrando a Pinacoteca para outra pessoa.Apenas um estava sozinho, morador do Rio Grande do Sul e que passou por todas as salas da Pinacoteca em apenas 38 minutos. Uma boa parte dos visitantes afirmou ter percorrido todas as salas da exposição de longa duração quando, na verdade, não o fez. Outros visitantes afirmaram 'não saber' se tinham ou não visto tudo, por dificuldades de orientação e identificação do conjunto, respostas, portanto, que indicam como eles tiveram dificuldade em reconhecer o conjunto da exposição.

\section{Os pontos de maior atração}

O espaço mais visitado foi o átrio com as "Esculturas Francesas". Cerca de $90 \%$ dos visitantes observados percorreram essa área da exposição de longa duração. Nesse espaço, muitos sentaram nos bancos disponíveis ${ }^{18}$. A

$18 \mathrm{Na}$ exposição havia 13 bancos: três deles nas salas de "Paisagens", sete nas salas com obras do século XIX (lado esquerdo do prédio), um numa das salas de "Arte Contemporânea" e dois bancos no átrio das "Esculturas Francesas". Os bancos, pelo que foi observado, exerceram um "poder de retenção", ou seja, quando são utilizados favorecem a permanência por mais tempo em um espaço. Entretanto, não se pode afirmar que exercem "poder de atração", ou seja, favorecem a entrada de uma pessoa num 
vitrine que trata da técnica da "cera perdida" foi um dos pontos de atração e retenção desta parte da exposição. Muitos visitantes param para ler uma parte, ou todos os textos, sobre a técnica de confecção de esculturas em bronze.

As salas mais visitadas estão no lado esquerdo do prédio e abrigam obras do século XIX e início do XX: "Grande Salão", "Almeida Júnior" e "Pedro Alexandrino", visitadas, respectivamente, por $79 \%, 73 \%$ e $68 \%$ dos visitantes observados.

As salas das "Paisagens", que ficam ao fundo, tiveram visitação de cerca de $60 \%$ dos visitantes observados ("Paisagem Marinha, Rural e Urbana"); entretanto, as partes das salas que ficam atrás de painéis tiveram visitação abaixo de $50 \%$ dos visitantes.

Entre as obras mais observadas pelos visitantes ${ }^{19}$, estão as de Almeida Júnior, uma vez que $79 \%$ estiveram na sala e observaram, mesmo que rapidamente, uma ou mais obras. Entre elas, destaca-se "Caipira picando fumo", que além de ser uma das mais observadas é também uma das mais escolhidas para que as pessoas tirassem fotos ao seu lado.

Entre as obras mais observadas, várias estão no "Grande Salão", que foi a sala mais visitada: o tríptico "La Faiseuse d'Anges" de Pedro Weingartner (48\%), "Maternidade" de Eliseo Visconti (40\%) e "Proclamação da República" de Benedito Calixto (36\%). As duas primeiras estão numa mesma parede e a obra de Calixto está na parece oposta.

A obra "Fim de romance" de Antonio Parreira foi tão observada quanto a pintura "Maternidade" (40\%) e fica na sala de "Paisagens Rurais", que foi a nona mais visitada (60\%). Isso indica um grande poder de atração da obra, pois a maior parte daqueles que entraram na sala olharam para ela. Fenômeno semelhante aconteceu com a obra "Festa escolar no Ipiranga" de Salinas y Teruel (35\%), que está na sala "Paisagens Urbanas", visitada também por $60 \%$ dos observados.

A obra "Sem título, 1989" de Nuno Ramos, que ocupa uma das paredes da "Sala Contemporânea", visitada por 34\% dos visitantes observados, foi olhada por $25 \%$ dos visitantes, indicando alto grau de atração desta obra. Essa atração poderia ser talvez explicada pela dimensão da obra, pela textura, pelos materiais utilizados, pelas cores, enfim, são inúmeras possibilidades. Essa obra não está competindo com muitas outras, como ocorre com aquelas mostradas no "Grande Salão" ou na "Sala de Retratos".

Num sentido inverso, a obra "Escrava romana", de Oscar Pereira da Silva, foi observada apenas por 18\% dos visitantes, sendo que ela está no "Grande Salão" (a sala mais visitada).As possíveis explicações poderiam vir de sua pequena dimensão em comparação a outras obras da sala e a localização, atrás de um painel, próxima a uma porta pouco utilizada pelo público.

Os fatores que explicam a atração de uma obra, como já comentado anteriormente, não são poucos e nem são válidos para todas as pessoas. No caso de pinturas, variáveis como a dimensão da obra, as cores, a temática po-

determinado espaço.

19 Como a Pinacoteca do Estado apresentava uma quantidade muito grande de obras, decidimos que seriam registradas especialmente as paradas para ver as principais obras. A seleção dos destaques do acervo foi feita pela equipe de pesquisa e curadoria da Pinacoteca e somou 53 obras, entre obras do século XIX e XX. Todas as obras citadas podem ser visualizadas no website da Pinacoteca do Estado. Disponível em: <www.pinacoteca.org.br $>$. 
deriam explicar parcialmente a probabilidade de um visitante parar para olhá-la. Mas, outras variáveis também são relevantes: a localização da obra (isolada ou não, na altura dos olhos ou não, no início ou fim de percurso), o conhecimento prévio do artista e da obra, as preferências do visitante (por exemplo, por paisagens e não por retratos). Os pontos não percorridos e/ ou olhados

Assim como a atração de algumas obras, vários fatores poderiam explicar a não visitação de determinados espaços / salas: as temáticas das obras apresentadas, a localização, a arquitetura dos espaços e as preferências dos visitantes.

As salas menos visitadas estão na parte direita do prédio e exibem obras contemporâneas. Elas têm apenas uma porta de acesso (diferentemente das salas nas outras partes do prédio). Pelas observações verificamos que as pessoas vão à parte direita do prédio, pois $90 \%$ estiveram no átrio das "Esculturas Francesas”, que fica desse lado. Muitas pessoas olham algumas obras das salas apenas pelos vidros. As partes das salas que ficam atrás de painéis e que exigem a 'exploração' por parte dos visitantes são as menos percorridas. É o caso da parte do "Abstracionismo Geométrico", que tem as obras de W. Cordeiro e outros (25\%) e a sala dedicada a "Willys de Castro", percorrida apenas por $19 \%$ dos visitantes observados.

Não é possível saber se há uma "rejeição" às obras de Willys de Castro, se a localização impede ou dificulta de tal maneira o acesso às suas obras que ele permanece 'desconhecido' ou a mistura desses fatores.

\section{As obras preferidas / As obras não apreciadas}

Perguntamos a 126 visitantes sobre o que mais gostaram. Muitos visitantes citaram nomes de artistas e nomes de obras. $O$ artista mais apreciado foi Almeida Júnior (I 5 citações), seguido por Tarsila do Amaral (7 citações), Portinari (6 citações) e Rodin (5 citações).

As obras mais citadas foram "Esculturas francesas" (6 citações), "Via Sacra" de Brecheret (4 citações), “Moema Morta” de Bernardelli e "Cinzas" de Pazé (ambas com 3 citações). É interessante notar que as obras citadas não constam na lista dos destaques da exposição do acervo da Pinacoteca.Também é interessante verificar que o nome de artistas é mais citado do que obras específicas, sinalizando uma possível valorização maior do artista do que de determinadas obras. Entre os artistas mais citados como preferidos,Almeida Júnior é aquele que tem mais obras em exposição ${ }^{20}$ e conta com uma sala própria.Tarsila do Amaral só tem uma obra na exposição e Portinari tem quatro obras ${ }^{2 !}$.

No caso de Rodin, há sete obras, mas é possível que alguns não percebam que há obras de outros escultores franceses (uma de Bourdelle e uma de Maillol) entre o conjunto de esculturas apresentado.

As "esculturas" foram muito apreciadas e houve 20 citações como o de que "mais gostou". As pinturas foram citadas por oito visitantes, entre os 126. Essa frequência é coerente com o grande número de visitantes que foram para o átrio das Esculturas Francesas (cerca de $90 \%$ dos visitantes), o das Esculturas Brasileiras (60\%) e Esculturas do Século XX (58\%), indicando apreciação pelas obras desses espaços.

20 Na exposição há 3 I obras de Almeida Júnior: I 5 na sala "Almeida Jr.", uma na sala "Natureza morta”, I I na sala "Retratos", uma na sala "Paisagem rural", duas na sala "Paisagem urbana" e uma no "Grande Salão". 
É difícil afirmar quais seriam as obras não apreciadas. Alguns poucos visitantes declararam preferir obras do século XIX, outros afirmaram preferir obras mais recentes e poucos disseram não gostar de obras "contemporâneas" ou "do século XIX". Se a não visitação de algumas salas indicasse a rejeição de determinadas obras, isso poderia sugerir que muitos visitantes não gostam das obras modernas e contemporâneas. Mas me parece muito arriscado afirmar qualquer coisa a respeito disso, apenas a partir dos dados obtidos nesta pesquisa.

Aliando entrevistas à observação dos visitantes, foi possível obter uma série de informações sobre a experiência da visita, entretanto, nem sempre foi possível determinar as causas, explicar os comportamentos e opiniões manifestadas.

\section{Considerações sobre a observação dos visitantes}

Concordo com Falk e Dierking $(1992,2000)$ quando afirmam que a experiência no museu é complexa e está ligada a fatores do "contexto pessoal", do "contexto físico" e "contexto sociocultural" e, nem sempre, por meio das pesquisas, se consegue identificar todos os fatores envolvidos.

As principais variáveis que podem ser registradas por meio da observação de percurso (timing and tracking) são:

I. Comportamentos de paradas (tempo total em salas, número de paradas, proporção de visitantes que param em um elemento específico, tempo de parada, tempo realizando atividades que não se relacionam com exposição, como falar ao celular).

2. Outros comportamentos (percurso, interações com seu grupo, com outros visitantes, com servidores do museu, manipulação de objetos e observação e vídeos).

3. Variáveis demográficas observáveis (idade estimada, número de pessoas no grupo e gênero).

4. Variáveis situacionais (número total de visitantes no museu, mês ou estação do ano, dia da semana, horário, temperatura ambiente, eventos e programas realizados no museu e na exposição, presença de servidores do museu ou outras situações que podem afetar o comportamento do visitante) (YALOWITZ; BRONNENKANT, 2009, p. 49-50).

É recomendável combinar a observação com outras estratégias, especialmente a entrevista.A possibilidade de fazer essa entrevista no espaço visitado, retomando opiniões e comportamentos dos visitantes, pode ser muito positiva para a compreensão do que o levou a determinados comportamentos ou opiniões. A utilização de fotografias, nos moldes da metodologia da "lembrança estimulada" poderia também auxiliar no aprofundamento do entendimento da experiência no museu.

As dificuldades enfrentadas pela utilização da observação estão relacionadas à necessidade de pessoal qualificado (tempo de formação), tempo para a pesquisa, um possível constrangimento do visitante (normalmente se recomenda abortar a observação quando o visitante se sente incomodado) e invasão de sua privacidade (mesmo que consentida) e a inexatidão na coleta de dados (por exemplo, se um visitante de fato olhou e observou uma obra ou se estava diante dela sem dar atenção à mesma). 
Apesar das dificuldades, concordo com Yalowitz e Bronnenkant (2009, p. 62) quando afirmam as vantagens do método da observação dos visitantes, por fornecer muitas informações relevantes para avaliar as exposições:

Timing and tracking has become one of the most consistently used methods in exhibition evaluation, because it is able to indicate the extent to which visitors are behaving in the expected and intended manner. Whether you are using traditional paper-and-pencil techniques, or the most recent technologies, a timing and tracking study provides a wealth of information about the target exhibition, which is also valuable in designing future exhibitions.

A metodologia de observação dos visitantes de museus não traz as respostas para todas as nossas perguntas, porém ela permite elaborar meIhor as questões para encaminhamento das pesquisas. É necessário somar a essa metodologia, outras tipos de estratégias, como a entrevista, a aplicação de questionários, o registro em audiovisual para que o visitante possa se ver explicar seu comportamento, entre outros.

\section{Referências}

ALMEIDA, A. M. Evaluation of school visits to the long-term exhibition 'Lasar Segall: constructions and poetics of an oeuvre'. In:DUFRESNE-TASSE, Colette (Org.). L'évaluation, recherche apliquée aux multiples usages. Québec:Éditions MultiMondes, 2002. p. 307-32I.

ALMEIDA, A. M. O contexto do visitante na experiência museal: semelhanças e diferenças entre museus de ciência e de arte. História, Ciências, Saúde-Manguinhos, v. 12, p. 31-53, 2005.

ALMEIDA,A. M. Os visitantes do Museu Paulista: um estudo comparativo com os visitantes da Pinacoteca do Estado e do Museu de Zoologia. Anais do Museu Paulista, v. I2, p. 269-306, 2004.

ALMEIDA, A. M.Avaliações da exposição de longa duração 'Lasar Segall: construção e poética de uma obra' e de sua ação educativa. São Paulo: Museu Lasar Segall, 200I. (Relatório geral).

ALMEIDA, A. M. Relatório final: avaliação da exposição de longa duração (exposição do acervo) da Pinacoteca do Estado. [S.I.: s.n.], 2008. No prelo.

BIGMAN, S. K. Art exhibit audiences: selected findings on who comes? Why? With what effects? Museologist, n. 59/60, p. 6-16, 1956.

BORUN, M.; CHAMBERS, M.; CLEGHORN,A. Families are learning in Science Museums. Curator:The Museum Journal, v. 39, n. 2, p. I23-I38, Jun. 1996.

CAZELLI, Sibele. Alfabetização científica e os museus interativos de ciências. 1992. 163 f. Dissertação (Mestrado)-Departamento de Educação, Pontifícia Universidade Católica, Rio de Janeiro, 1992.

DAVEY, G.What is museum fatigue?Visitors Sudies Today, v. 8, n. 3, p. 17-2I, 2005.

DUTRA, Soraia Freitas Dutra.A educação na fronteira entre museus e escolas: um estudo sobre as visitas escolares ao Museu Histórico Abílio Barreto. 2012. Tese (Doutorado)-Faculdade de Educação, Universidade Federal de Minas Gerais, 2012. 
FALCÃO, D.; GILBERT,J. K. Método da lembrança estimulada: uma ferramenta de investigação sobre aprendizagem em museus de ciências. História, Ciências, Saúde-Manguinhos (impresso), Rio de Janeiro, v. I2, n. I0, p. 9 I-I I 5, 2005.

FALK, J.; DIERKING, L. Learning from museums: visitor experiences and the making of meaning. Boston:Altamira Press, 2000.

FALK, J., DIERKING, L.The museum experience.Washington DC:Whalesback Books, 1992.

FALK, J.The use of time as a measure of visitor behavior and exhibit effectiveness. Roundtable Reports, v. 7, n. 4, p. 10-13, 1982.

FREIRE, Beatriz Muniz. $O$ encontro museu/escola: o que se diz e o que se faz. 1992. I34 p. Dissertação (Mestrado)-Departamento de Educação, Pontifícia Universidade Católica, Rio de Janeiro, 1992.

GARCIA, V. A. R. O processo de aprendizagem no Zoológico de Sorocaba: análise da atividade educativa, visita orientada a partir dos objetos biológicos. 2006. 224 f. Dissertação (Mestrado em Educação)-Faculdade de Educação, Universidade de São Paulo, 2006.

GILMAN, B. I. Museum fatigue. The Scientific Monthly, v. 2, p. 62-74, 1916.

GOINS, A.; GRIFFEHAGE, G. Psychological studies of museum visitors and exhibits at the US National Museum. Museologist, n. 64, p. I-6, 1957.

KÖPTCKE, L. S.; PEREIRA, M. R. N. Museus e seus arquivos: em busca de fontes para estudar os públicos. História, Ciências, Saúde - Manguinhos, v. I7, n. 3, p. 809-828, jul./set. 2010.

LAWRENCE, G. Remembering rats, considering culture: perspectives on museum evaluation. In: BICKNELL, S.; FARMELO, G. (Ed.). Museum visitor studies in the 90s. London: Science Museum, 1993. p. I $17-124$.

LUTZ, B.A função educativa dos museus. Organizadores: Guilherme Miranda et al. Rio de Janeiro: Museu Nacional, 2008.

MELTON,A.; FELDMAN, N. G.; MASON, C.W. Measuring museum based learning: experimental studies of the education of children in a museum of science. Washington DC:American Association of Museums, 1996. (New Series, n. I5).

MELTON, A.W. Distribution of attention in galleries in a museum of science and industry. Museum News, v. XIV, n. 3, p. 5-8, June 1936.

ROBINSON, E. Introduction. In: MELTON, A.; FELDMAN, N. G.; MASON, C. W. Measuring museum based learning: experimental studies of the education of children in a museum of science. Washington DC:American Association of Museums, 1996. (New Series, n. I5).

ROBINSON, E. The behaviour of the museum visitor. Washington DC:American Association of Museums, 1928. (New series, n. 5).

SÁPIRAS, A. Aprendizagem em museus: uma análise das visitas escolares no Museu Biológico do Instituto Butantan. 2007. 155 f. Dissertação (Mestrado em Educação)-Faculdade de Educação, Universidade de São Paulo, 2007.

VALENTE, M. E.A. Educação em museus: o público de hoje no museu de on- 
tem. 1995. 208 f. Dissertação (Mestrado em Educação)-Pontifícia Universidade Católica, Rio de Janeiro, 1995.

VERÓN, E.; LEVASSEUR, M. Ethnographie de l'exposition:l'espace, le corps et le sens. Paris: Centre Georges Pompidou, 1989.

WOLF, R. L.A naturalistic view of evaluation. Museum News, v. 58, n. 6, p. 39 45, July/Aug. 1980. 